\title{
The Impacts of Training on Turnover Intention of Chinese Millennials
}

\author{
Genping $\mathrm{Ye}^{1}$
}

\author{
${ }^{1}$ The University of Manchester \\ *genping.ye689@outlook.com
}

\begin{abstract}
The purpose of this research is to look into the correlation between Chinese millennial training, job satisfaction, and intention to quit. Critical research has focused on defining the three main factors in order to investigate their complex interactions. Similarly, there has been little research on millennials when considering these complex issues. This study used a quantitative questionnaire to assess the impact of training on millennials' turnover intentions. The findings revealed a link between training and the desire of millennials to quit. To be more specific, it demonstrates that the availability of training, the motivation for training, and the benefits of training successfully diminish millennials' desire to leave, but support of training has no considerable impacts on turnover. The study, in theory, fills in the gaps in the literature linking millennial departure to training in the Chinese environment. In practice, it would assist managers in advancing human resource management policies, such as training programmes.
\end{abstract}

Keywords: Turnover intention, training, job satisfaction, millennials

\section{INTRODUCTION}

Recently, a growing body of literature has focused on employee turnover, especially among millennials. As the exploration goes in-depth, researchers have paid more and more attention to the relationship between training and millennial turnover intention. There are certain holes, however, in the current research. To begin with, there is little research on the trends of millennial turnover tendencies and the reasons for the high turnover rate among unique Chinese millennials. Besides, few studies have looked at whether their distinctiveness might result in unexpected or more complicated aspects refer to the training-to-turnover intention link. Thus, it is still unclear whether training has a beneficial or detrimental impact on millennial turnover intentions in China. Furthermore, Chinese millennials value job satisfaction because they place a greater emphasis on their emotions [1]. Practical training has been proposed to promote job satisfaction, which is important to reduce turnover [2]. However, research on whether job satisfaction can moderate the link between training and millennial turnover in China is deficient.

Through empirical research, this study finds that training, work satisfaction and turnover intention of Chinese millennials are significantly correlated. Firstly, the correlation between training and work satisfaction, training and Chinese millennial turnover, job satisfaction and Chinese millennial turnover is tested through correlation regression research. Then, the mediating role of job satisfaction between training and millennial dimission is explored through mediating analysis. The analysis was based on data from a hightech firm with around $80 \%$ of whom born between 1981-1996, and a $15 \%$ of turnover rate in latest years.

\section{LITERATURE REVIEW}

\subsection{Millennial Employees}

In 1928, Mannheim was the first to introduce the generation hypothesis [3]. He defined a generation as a group of people born at the same time with similar life experiences and social changes [3]. Due to the comparable growth environment, $\mathrm{Yi}$ added that one generation might shares the similar ideas, beliefs, and experience [1]. The four generations usually characterized are Baby Boomers (birthed between 19461964), Generation X (birthed between 1965-1980), Generation Y or Millennials (birthed between 19811996), and Generation Z or Zoomers (birthed after 1996) [3]. 
Chinese millennials are a unique generation because of China's one-child policy in 1979 [4], which stipulates that in order to control population growth, each family is allowed to have only one child. In this case, most millennials are the only child in their household. Compared to other groups who grew up with siblings, they are more self-centered and less willing to give [5]. In addition, the "one-child policy" also gives rise to a "four-two-one" family structure referring to the four grandparents, two parents, and one child [2]. As a result, the only child becomes the "little emperor", overtreated and self-centered. This characteristic is evident when comparing millennials in China with their counterparts in other countries [6].

In workplace, Chinese millennials are known for their frequent job-hopping. According to the Human Resource Management Report (2019), Millennials have a turnover rate of about $24 \%, 5 \%$ higher than the average for all employees [7]. Furthermore, Chinese millennials stay on one organization for 2.5 years averagely, about half a year less than in the United States [8]. This tendency might result from their self-centered personality. Moreover, characteristics such as a need for autonomy and challenge are associated with low job satisfaction [4]. When these individuals believe that the companies are failing to meet their needs, they will choose to leave their jobs. There are also the external issues, including the financial pressures to support the entire family [1].

\subsection{Relationships between Training, Job Satisfaction and Turnover Intention}

Training is the process of educating people how to enhance their talents in areas that are important to certain valuable competences [9]. It is a systematic programme that instructs and teaches individuals vital technical information and competencies relevant to their responsibilities in the workplace. Bulut and Culha define training as a multidimensional framework that includes the availability, motivation, support and benefits of training [10]. It denotes employees' views, including attitude and training evaluation, which is more relevant to the goal of this study to examine the employee's attitudes, whereas other dimensions focus on training programme evaluation.

Training has been demonstrated in numerous studies to have a significant influence on work satisfaction, which refers to employee satisfaction with the psychological and physiological aspects of their jobs [11]. Jones and other authors claim that in German, there is no substantial link between training and work satisfaction [12]. However, there are many people who support the negative correlation between job satisfaction and training. Zhao claims that millennials value job satisfaction more than previous generations in China [4].
The link between training and voluntary turnover intention, employees' willingness to leave an organization, is a hot topic of discussion. On the one hand, many academics believe that training would boost retention motivation [13]. Some experts, on the other hand, claim that employees who have made progress in their abilities would have higher intention to leave their jobs in search of better prospects for better advancement [14]. Despite numerous studies have focused on the influence of training on employee intention to leave, few have looked at the unique characteristics of Chinese millennials. In other words, it is recommended to proof the correlation between training and Chinese millennial employee turnover.

Much research has looked into the role of organizational commitment as a mediating factor [15], however, there is a paucity of research on the mediating role of job satisfaction. Yi, on the other hand, claims that Chinese millennials care less about organisational loyalty due to their passion for freedom [6]. If organisational commitment plays a mediating role in this investigation, it will affect the validity and reliability of the study. Job satisfaction, according to Costen and Salazar, can serve as a mediator since Chinese millennial workers place a high value on it [16]. However, there is a gap in the literature because little research has been done on the function of work satisfaction in moderating the correlation between training and millennial intentions to leave.

\section{MERHODOLOGY AND METHODS}

The goal of the study is to understand how training affects Chinese millennial employees. The following is a diagram of the conceptual research model:

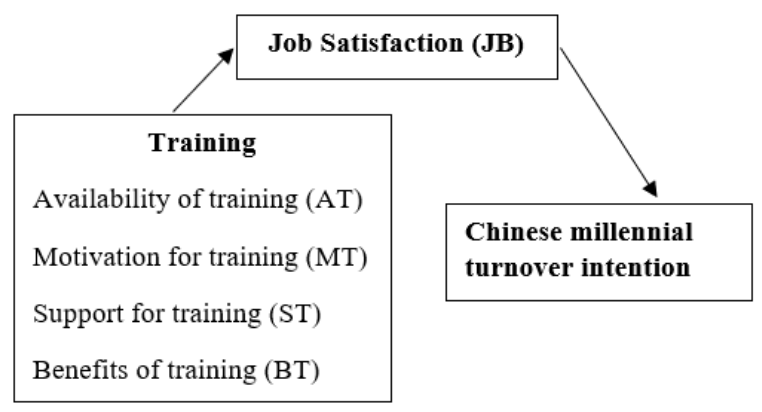

Figure 1 Research model (developed by author)

\subsection{Data Collection Methods}

This research creates a questionnaire with four components and 33 questions. It begins with demographic questions for participants, followed by a section on employee opinions of training. The employee's overall job satisfaction is surveyed in the third section, which is followed by the investigation of the turnover intention of the employees. The last three sections are evaluated by a five-item Likert scale, which 
splits agreement into five levels. "Strongly disagree," "disagree," "neither agree nor disagree," "agree," and "strongly agree," respectively, are represented by 1, 2, 3, 4 , and 5 .

To create online questionnaires, this study employs the programme questionnaire star, a functional and consumer-friendly tool to collect questionnaires. This questionnaire link is provided by emails and social media platforms like WeChat.

\subsection{Measurement}

The measurement of variables is based on the current literature and has been proved to be accurate and valid by a large number of academics. The training measurement is based on a study by Newman in the Chinese environment [17]. It includes four items to assess training availability and training motivation, six items to assess training assistance and training benefits. The Michigan Organizational Assessment Questionnaire, established by Cammann and Fichman, is used to measure job satisfaction [15]. It contains three items to evaluate general job satisfaction. The Arnold and Davey Employee Turnover Scale is used to measure the employee turnover intention, which consists of four components [11].

\subsection{Sampling Population}

This study employs basic random sampling to ensure that all population members have equal access to the questionnaire. The study focuses on millennial employees born between 1981 and 1996. The company chosen for this study is Company B in Shandong, China, which is involved in the production of electric vehicles. It builds five huge bases around China and employs almost 3000 people, the majority of them millennials, with a turnover rate of about $15 \%$ in recent years. The organization also provides professional training for employees. With its huge number of millennial employees and diverse training programmes, the company would provide research samples.

\section{DATA ANALYSIS}

This study will look at quantitative data from questionnaires. This study includes 245 online surveys, of which 223 are effective, with an overall response rate of $91 \%$.

\subsection{Reliability Analysis}

When Alpha $(\alpha)$ is more than 0.7, data is considered to be reliable [18]. The reliability of this study based on SPSS software is shown in Table 1.

Table 1 shows that the Alpha $(\alpha)$ of training availability, motivation for training, support for training, benefits of training, job satisfaction, and turnover intention are all greater than 0.8 , with the values of $0.863, \quad 0.855, \quad 0.871, \quad 0.891, \quad 0.733, \quad$ and 0.891 respectively, indicating excellent reliability. Overall, the questionnaire has a high level of dependability.

Table 1 Reliability Analysis

\begin{tabular}{c|c|c}
\hline Factors & Cronbach's Alpha & N of Items \\
\hline AT & .863 & 4 \\
\hline MT & .855 & 4 \\
\hline ST & .871 & 6 \\
\hline BT & .891 & 6 \\
\hline JS & .733 & 3 \\
\hline TI & .891 & 4 \\
\hline
\end{tabular}

\subsection{Validity Analysis}

When KMO is greater than 0.7 and Sig is less than 0.05 , the questionnaire processes good validity [15] Effectiveness analysis results are as follows, based on SPSS analysis:

Table 2 Perceptions of Training KMO and Bartlett's Test

\begin{tabular}{c|c|c}
\hline \multicolumn{2}{c|}{$\begin{array}{c}\text { Kaiser-Meyer-O1kin Measure of } \\
\text { Sampling Adequacy. }\end{array}$} & .824 \\
\hline $\begin{array}{c}\text { Bartlett's Test of } \\
\text { Sphericity }\end{array}$ & $\begin{array}{c}\text { Approx. Chi- } \\
\text { Square }\end{array}$ & 417.836 \\
\hline & df & 6 \\
\hline & Sig & .000 \\
\hline
\end{tabular}

Table 2 demonstrates that $\mathrm{KMO}=0.824>0.7$, Sig $=0.000<0.05$, indicating high training perceptual validity.

Table 3 Job Satisfaction KMO and Bartlett's Test

\begin{tabular}{c|c|c}
\hline \multicolumn{2}{c|}{$\begin{array}{c}\text { Kaiser-Meyer-O1kin Measure of } \\
\text { Sampling Adequacy. }\end{array}$} & .756 \\
\hline $\begin{array}{c}\text { Bartlett's Test of } \\
\text { Sphericity }\end{array}$ & $\begin{array}{c}\text { Approx. Chi- } \\
\text { Square }\end{array}$ & 382.278 \\
\hline & df & 5 \\
\hline & Sig & .000 \\
\hline
\end{tabular}

As shown in Table 3, the value of KMO is 0.756 , higher than 0.7 and that of Sig is $0.000<0.05$, which suggests that work satisfaction has good validity.

Table 4 Turnover Intention KMO and Bartlett's Test

\begin{tabular}{c|c|c}
\hline \multicolumn{2}{c|}{$\begin{array}{c}\text { Kaiser-Meyer-O1kin Measure of } \\
\text { Sampling Adequacy. }\end{array}$} & .843 \\
\hline $\begin{array}{c}\text { Bartlett's Test of } \\
\text { Sphericity }\end{array}$ & $\begin{array}{c}\text { Approx. Chi- } \\
\text { Square }\end{array}$ & 499.337 \\
\hline & df & 6 \\
\hline & Sig & .000 \\
\hline
\end{tabular}

Table 4 shows that $\mathrm{KMO}=0.843>0.7$ and $\mathrm{Sig}=0.000<0.05$, indicating that turnover intention has good validity. 


\subsection{Descriptive Analysis}

The descriptive analysis explains the data range and helps determine correlations between variables. The following is a description of the questionnaire's descriptive analysis.

Table 5 reveals that the mean values of all training variables are greater than the median value (3), among which training advantage is the largest (3.330) and training motivation is the lowest (3.216). The average value of job satisfaction is 3.303 , which is higher than 3 . In contrast, the mean value of turnover intention is 2.575 , which is lower than 3 , indicating that individual turnover intentions are lower than the median level overall.

\subsection{Correlation Analysis}

The study of the link between variables is known as correlation [18]. Pearson's coefficient is extensively used to assess the relationship between variables [18]. Table 6 shows the results of the measurements.

The results of the correlation study are summarized in Table 7. It demonstrates that there is a favorable correlation between four factors of training (availability of training, motivation of training, support of training, benefits of training) and work satisfaction (Pearson Correlation is $0.423 * *, \quad 0.433^{* *}, \quad 0.369^{* *}$, $0.487 * *$ respectively, $\mathrm{P}<0.01)$. Furthermore, except for support of training (Pearson Correlation=-.074, $\mathrm{P}>0.05$ ), there is a negative association among three characteristics of training and turnover intention (Pearson Correlation is $-0.486 * *,-0.337 * *$, $0.490 * *$ respectively, $\mathrm{P}<0.01$ ). In a similar vein, work satisfaction is found to have a medium negative connection with the intention to leave (Pearson Correlation $=-0.503 * *, \mathrm{P}<0.01)$.

\subsection{Regression Analysis}

The goal of regression analysis is to figure out how variables work together. According to Saunders, multiple linear regression analysis is often used to examine correlations, which is done in this study [18]. The impact of the predictor variable on the dependent variable is shown by value $\mathrm{B}$ in a multiple regression analysis. A positive correlation is defined as $\mathrm{B}>0$, whereas a negative correlation is denoted as $\mathrm{B}<0$ [18].

This regression model is significant, as shown in table 8, with $\mathrm{Sig}=0.000$. As $\mathrm{Sig}=0.001<0.05, \mathrm{~B}=-0.232$ shows, there is a significant negative correlation between availability of training and the desire to turnover; $\mathrm{Sig}=0.044<0.05, \mathrm{~B}=-0.147$ (motivation for training) reveals that motivation for training would affect the willingness to leave negatively; Sig $=0.153>0.05$ (support of training) shows that there is no relationship between support of training and intention to quit; $\mathrm{Sig}=0.000, \mathrm{~B}=-$ 0.2480 (benefits) shows that benefits of training would influence positively the retention to stay; Work satisfaction has a strong negative impact on turnover, as indicated by $\mathrm{Sig}=0.000, \mathrm{~B}=-0.345$ (job satisfaction).

To summarize, turnover intention $=$ 0.232 availability of training -0.147 motivation for training -0.248 benefits of training -0.345 job satisfaction +6.127 .

The association between training and work satisfaction can be displayed in Table 9. The significance of the regression model is indicated by $\mathrm{Sig}=0.000$. It proofs that availability of training $(B=0.289$, Sig $=0.000)$, motivation for training $(B=0.195, \quad \mathrm{Sig}=0.003<0.05)$, support for training $(\mathrm{B}=0.189$, Sig=0.004<0.05), and benefits of training $(B=0.340, \mathrm{Sig}=0.000)$ have a positive impact on work satisfaction.

The regression equation: job satisfaction = 0.289 availability of training +0.195 motivation for training +0.189 support of training +0.340 benefits of training +2.186

\subsection{Mediating Effect Analysis}

The mediating effect is the influence of the mediating independent variable (IV) on the dependent variable (DV) [18]. $\mathrm{M}$ is the mediator role mediating the link between $\mathrm{X}$ and $\mathrm{Y}$, assuming $\mathrm{X}, \mathrm{Y}, \mathrm{M}$ are independent, dependent and mediating variables respectively. The investigation of the mediating effect consists of three steps. First, X has a significant relationship with Y; Second, $\mathrm{X}$ is significantly correlated with M. Finally, the relationship between $\mathrm{X}$ and $\mathrm{Y}$ changes when $\mathrm{M}$ is included in the regression equation [18].

Table 10 shows that $\mathrm{t}=-8.341 * * *$ (step 1$)$ indicates a significant correlation between availability of training and the willingness to leave; A substantial association exists between the availability of training and work satisfaction, as indicated by $\mathrm{t}=9.530 * * *$ (step 2). Step 3 indicates that, indicates that job satisfaction reduces the relationship between training availability and the desire to leave $(\beta=-0.205>-0.486)$. As a result, work satisfaction acts as a mediator between the availability of training and the likelihood of turnover.

Table 11 shows a significant association between training motivation and the intention to resign $(\mathrm{t}=-$ $6.733^{* * *}$ in step 1); Step $2\left(\mathrm{t}=6.161^{* * *}\right)$ shows that motivation of training and job satisfaction have a significant correlation; and $\beta=-0.142>-0.374$ in step 3 shows that work satisfaction acts as a mediating factor to reduce the association between training motivation and the willingness to quit.

Table 12 shows that it lacks significant link between training support and the desire to resign $(\mathrm{t}=0.207$ in step 1), ruling out the mediating influence of work satisfaction on training support and turnover intention. 
Table 13 shows that a substantial link between training and the willingness to leave $(\mathrm{t}=-8.997 * * *$ in step 1 ), as well as a significant association between training benefits and work satisfaction $(\mathrm{t}=6.489 * * *$ in step 2$)$. Step 3 indicates that work satisfaction reduces the relationship between training benefits and the desire to quit $(\beta=-0.256>-0.490)$.
To summarise, work satisfaction plays a mediating role in the association between three training qualities (availability, motivation, benefits) and the desire to leave, but not between training support and the willingness to leave.

Table 5 Descriptive analysis

\begin{tabular}{c|c|c|c|c|c}
\hline \multicolumn{5}{c}{} & \multicolumn{2}{c}{ Std } \\
\hline & $\mathrm{N}$ & Minimum & Maximum & Mean & Deviation \\
\hline AT & 223 & 1.00 & 5.00 & 3.2220 & .76454 \\
\hline MT & 223 & 1.00 & 5.00 & 3.2164 & .70551 \\
\hline ST & 223 & 1.00 & 5.00 & 3.2384 & .66331 \\
\hline BT & 223 & 1.00 & 5.00 & 3.3303 & .73657 \\
\hline JS & 223 & 1.00 & 5.00 & 3.3034 & .72657 \\
\hline TI & 223 & 1.00 & 5.00 & 2.5751 & .80344 \\
\hline
\end{tabular}

Table 6 Measurements of Pearson's coefficient (PC)

\begin{tabular}{c|c}
\hline $0<$ Pearson's coefficient $<0.4$ & Low degree of positive correlation \\
\hline $0.4<$ Pearson's coefficient $<0.7$ & Medium degree of positive correlation \\
\hline $0.7<$ Pearson's coefficient $<1$ & High degree of positive correlation \\
\hline$-0.4<$ Pearson's coefficient $<0$ & Low degree of negative correlation \\
\hline$-0.7<$ Pearson's coefficient $<-0.4$ & Medium degree of negative correlation \\
\hline$-1<$ Pearson's coefficient $<-0.7$ & High degree of negative correlation \\
\hline
\end{tabular}

Table 7 Correlation analysis

\begin{tabular}{|c|c|c|c|c|c|c|c|}
\hline & & AT & MT & ST & BT & JS & $\mathrm{TI}$ \\
\hline AT & $P C$ & 1 & & & & & \\
\hline $\mathrm{MT}$ & $P C$ & $.479^{\star \star}$ & 1 & & & & \\
\hline ST & $P C$ & $.369^{\star \star}$ & $.356^{\star *}$ & 1 & & & \\
\hline BT & $P C$ & $.494^{\star *}$ & $.402^{\star *}$ & $.392^{\star \star}$ & 1 & & \\
\hline JS & $P C$ & $.423^{\star \star}$ & $.433^{\star \star}$ & $.369^{\star *}$ & $.487^{\star \star}$ & 1 & \\
\hline $\mathrm{TI}$ & $\mathrm{PC}$ & $-.486^{\star \star}$ & $-337^{\star \star}$ & -.074 & $-.490^{\star \star}$ & $-.503^{\star \star}$ & 1 \\
\hline
\end{tabular}

**. Correlation is significant at the 0.01 level (2-tailed); ** represents that the significance at $1 \%$ level $(\mathrm{P}<0.01)$; *represents the significance at $5 \%$ level $(\mathrm{P}<0.05)$; the value without $*$ or $* *$ means the uncorrelated relationship between two factors.

Table 8 The impact of training and job satisfaction on turnover intention

\begin{tabular}{c|c|c|c|c|c}
\hline & \multicolumn{2}{|c|}{ Unstandardised Coefficients } & \multicolumn{3}{c}{ Unstandardised Coefficients } \\
\hline Model & B & Std. Error & Beta & $\mathrm{t}$ & Sig. \\
\hline (Constant) & 6.127 & .098 & & 62.647 & .000 \\
\hline AT & -.232 & .068 & -.221 & -3.392 & .001 \\
\hline MT & -.147 & .073 & -.129 & -2.024 & .044 \\
\hline ST & -.113 & .078 & .093 & -1.435 & .153 \\
\hline BT & -.248 & .068 & -.228 & -3.677 & .000 \\
\hline JS & -.345 & .069 & -.312 & -5.002 & .000 \\
\hline Adjusted R2 & \multicolumn{2}{|c|}{0.873} & & & \\
\hline Sig & \multicolumn{2}{|c|}{0.000} & & & \\
\hline
\end{tabular}


a. Dependent Variable: Turnover intention

Table 9 The impact of training on job satisfaction

\begin{tabular}{c|c|c|c|c|c}
\hline & \multicolumn{2}{|c|}{ Unstandardised Coefficients } & \multicolumn{3}{c}{ Unstandardised Coefficients } \\
\hline Model & B & Std. Error & Beta & $\mathrm{t}$ & Sig. \\
\hline (Constant) & 2.186 & .098 & & 1.910 & .000 \\
\hline AT & .289 & .064 & .305 & 4.504 & .000 \\
\hline MT & .195 & .070 & .190 & 2.778 & .003 \\
\hline ST & .189 & .076 & .187 & 1.819 & .004 \\
\hline BT & .340 & .062 & .345 & 5.472 & .000 \\
\hline Adjusted R2 & \multicolumn{2}{|c|}{0.847} & & & \\
\hline Sig & \multicolumn{2}{|c|}{0.000} & & & \\
\hline
\end{tabular}

a. Dependent Variable: Job satisfaction

Table 10 mediating effect between the availability of training and turnover intention

\begin{tabular}{c|c|c|c|c|c|c|c|c}
\hline $\begin{array}{c}\text { Model } \\
\text { assumption }\end{array}$ & Step & DV & IV & $\beta$ & SE & $\mathrm{t}$ & $\begin{array}{c}\text { Adjusted } \\
\text { R2 }\end{array}$ & $\mathrm{F}$ \\
\hline $\mathrm{AT} \rightarrow \mathrm{JB} \rightarrow \mathrm{TI}$ & 1 & $\mathrm{TI}$ & $\mathrm{AT}$ & -0.486 & 0.032 & $-8.341^{\star * *}$ & 0.191 & $83.190^{\star \star *}$ \\
\hline & 2 & $\mathrm{JB}$ & $\mathrm{AT}$ & 0.423 & 0.032 & $9.530^{\star \star *}$ & 0.297 & $72.049^{\star \star *}$ \\
\hline & 3 & $\mathrm{TI}$ & $\mathrm{AT}$ & -0.205 & 0.060 & $-5.665^{\star \star *}$ & 0.345 & $63.615^{\star \star *}$ \\
\hline & & & $\mathrm{JB}$ & -0.411 & 0.065 & $-9.379^{\star \star *}$ & & \\
\hline
\end{tabular}

Table 11 mediating effect between motivation of training and turnover intention

\begin{tabular}{c|c|c|c|c|c|c|c|c}
\hline $\begin{array}{c}\text { Model } \\
\text { assumption }\end{array}$ & Step & DV & IV & $\beta$ & SE & $\mathrm{t}$ & $\begin{array}{c}\text { Adjusted } \\
\text { R2 }\end{array}$ & $\mathrm{F}$ \\
\hline $\mathrm{MT} \rightarrow \mathrm{JB} \rightarrow \mathrm{TI}$ & 1 & $\mathrm{TI}$ & $\mathrm{MT}$ & -0.374 & 0.040 & $-6.733^{\star \star *}$ & 0.163 & $74.095^{\star \star *}$ \\
\hline & 2 & $\mathrm{JB}$ & $\mathrm{MT}$ & 0.433 & 0.360 & $6.161^{\star \star *}$ & 0.255 & $68.424^{* \star *}$ \\
\hline & 3 & $\mathrm{TI}$ & $\mathrm{MT}$ & -0.142 & 0.064 & $-4.845^{\star \star *}$ & 0.247 & $61.149^{\star \star *}$ \\
\hline & & & $\mathrm{JB}$ & -0.447 & 0.059 & $-7.972^{\star \star \star}$ & & \\
\hline
\end{tabular}

Table 12 mediating effect between support for training and turnover intention

\begin{tabular}{c|c|c|c|c|c|c|c|c}
\hline $\begin{array}{c}\text { Model } \\
\text { assumption }\end{array}$ & Step & DV & IV & $\beta$ & SE & $\mathrm{t}$ & $\begin{array}{c}\text { Adjusted } \\
\text { R2 }\end{array}$ & $\mathrm{F}$ \\
\hline $\mathrm{ST} \rightarrow \mathrm{JB} \rightarrow \mathrm{TI}$ & 1 & $\mathrm{TI}$ & $\mathrm{ST}$ & -0.074 & 0.068 & 0.207 & 0.003 & 0.103 \\
\hline & 2 & $\mathrm{JB}$ & $\mathrm{ST}$ & & & & & \\
\hline & 3 & $\mathrm{TI}$ & $\mathrm{ST}$ & & & & & \\
\hline & & & JB & & & & & \\
\hline
\end{tabular}

Table 13 mediating effect between benefits of training and turnover intention

\begin{tabular}{c|c|c|c|c|c|c|c|c|c}
\hline $\begin{array}{c}\text { Model } \\
\text { assumption }\end{array}$ & & Step & DV & IV & $\beta$ & SE & $\mathrm{t}$ & $\begin{array}{c}\text { Adjusted } \\
\text { R2 }\end{array}$ & $\mathrm{F}$ \\
\hline $\mathrm{BT} \rightarrow \mathrm{JB} \rightarrow \mathrm{TI}$ & & 1 & $\mathrm{TI}$ & $\mathrm{BT}$ & -0.490 & 0.033 & $-8.997^{* \star *}$ & 0.291 & $84.813^{* \star *}$ \\
\hline & & 2 & $\mathrm{JB}$ & $\mathrm{BT}$ & 0.487 & 0.031 & $6.489^{\star \star *}$ & 0.285 & $81.622^{\star * \star}$ \\
\hline & & 3 & $\mathrm{TI}$ & $\mathrm{BT}$ & -0.256 & 0.061 & $-5.477^{\star \star \star}$ & 0.253 & $63.614^{\star \star \star}$ \\
\hline & & & & $\mathrm{JB}$ & -0.588 & 0.062 & $--7.484^{* \star *}$ & & \\
\hline
\end{tabular}




\section{CONCLUSION}

\subsection{Contributions}

Theoretically, the study gives specific attention to Chinese millennials in the workplace when examining the relationship between training, job satisfaction, and turnover intention, this study pays special attention to Chinese millennials in the workplace. It fills a gap in the literature that lacks in-depth research on this distinct demographic structure, as much of the literature focuses on the general workforce in Western countries. Furthermore, the study confirms a negative correlation between training and turnover intention, addressing a controversial topic and providing ample evidence for literature claiming that training has a favourable impact on millennial talent retention.

Practically, the findings of this study show that training can help millennials lower their willingness to leave. Employers and managers might learn more about how training and job satisfaction can keep millennials from leaving, which helps to deal with millennial brain drain. Moreover, this research may also provide a new perspective on millennial reservation for Chinese human resource managers. For example, when training programmes fail, human resource managers are encouraged to take specific remedial actions to reduce millennial turnover intentions.

\subsection{Conclusion}

Based on training and turnover intention theory, this study finds the impact of training on millennial turnover and the mediating function of work satisfaction in the association. This study empirically examined survey data from a Chinese high-tech company with a large number of millennial employees. The study reveals that the relationship between availability of training, motivation for training, benefits of training and millennial turnover intention are mediated by job satisfaction respectively by using correlation, regression, and mediating analysis. The findings may serve as a springboard for further research on related topics, as well as offer some recommendations for human resource management practices of knowledge workers. It is suggested to conduct research on millennials in various industries and provinces in China, so as to increase the sample size.

\section{REFERENCES}

[1] Yi X, Ribbens B, Morgan C N. Generational differences in China: Career implications[J]. Career Development International, 2010.

[2] Zheng H. An analysis of the relationship between effective on the job training and job satisfaction: a study of a language training school in China[D]. Dublin, National College of Ireland, 2017.

[3] Kupperschmidt B R. Multigeneration employees: strategies for effective management[J]. The health care manager, 2000, 19(1): 65-76.

[4] Zhao Y. Managing Chinese millennial employees and their impact on human resource management transformation: an empirical study[J]. Asia Pacific Business Review, 2018, 24(4): 472-489.

[5] Zhao Y, Xu Q. Understanding the achieving styles of Chinese millennials and implications on HRM policy: A life course perspective[J]. International Journal of Manpower, 2019.

[6] Yi X, Ribbens B, Fu L, et al. Variation in career and workplace attitudes by generation, gender, and culture differences in career perceptions in the United States and China[J]. Employee Relations, 2015.

[7] Carefree human resources research center, 'Human Resource ManagementReport 2019', 2019.

[8] LinkedIn, 'Insight into China', millennial business decision markers, 2018.

[9] Armstrong M, Taylor S. Armstrong's handbook of human resource management practice[J]. 2020.

[10]Bulut C, Culha O. The effects of organizational training on organizational commitment $[\mathrm{J}]$. International journal of training and development, 2010, 14(4): 309-322.

[11] Khan A A, Abbasi S, Waseem R M, et al. Impact of training and development of employees on employee performance through job satisfaction: A study of telecom sector of Pakistan[J]. Business Management and Strategy, 2016, 7(1): 29-46.

[12] Jones M K, Jones R J, Latreille P L, et al. Training, job satisfaction, and workplace performance in Britain: Evidence from WERS 2004[J]. Labour, 2009, 23: 139-175.

[13] Dardar A H A, Jusoh A, Rasli A. The impact of job training, job satisfaction and alternative job opportunities on job turnover in Libyan oil companies $[\mathrm{J}]$. Procedia-Social and Behavioral Sciences, 2012, 40: 389-394.

[14]Cheng Y, Waldenberger F. Does training affect individuals' turnover intention? Evidence from China[J]. Journal of Chinese Human Resources Management, 2013.

[15] Johnson N, Fields Z, Chukwuma N A. Training, Organisational Commitment and Turnover Intention among Nigerian Civil Servants[J]. 
Journal of Economics and Behavioral Studies, 2018, 10(6A (J)): 1-15.

[16] Costen W M, Salazar J. The impact of training and development on employee job satisfaction, loyalty, and intent to stay in the lodging industry[J]. Journal of Human Resources in Hospitality \& Tourism, 2011, 10(3): 273-284.

[17] Newman A, Thanacoody R, Hui W. The impact of employee perceptions of training on organizational commitment and turnover intentions: a study of multinationals in the Chinese service sector $[\mathrm{J}]$. The international journal of human resource management, 2011, 22(8): 1765-1787.

[18] Saunders M, Lewis P, Thornhill A. Research methods for business students[M]. Pearson education, 2009. 